\title{
The importance of general self-efficacy for the quality of life of adolescents with diabetes or juvenile rheumatoid arthritis over time: a longitudinal study among adolescents and parents
}

\section{Jane M. Cramm*, Mathilde M. H. Strating and Anna P. Nieboer}

Institute of Health Policy and Management, Erasmus University, Rotterdam, Netherlands

Edited by:

Amit Agrawal, Hamidia Hospital, India

Reviewed by:

Yinka Ayeni, Texas Tech University Health Sciences Center, USA

Kelly J. Ace, Family Support Line, USA

Lynn M. Breau, Glenrose

Rehabilitation Hospital, Canada

Kamel Gana, University of Bordeaux,

France

${ }^{*}$ Correspondence:

Jane M. Cramm, Institute of Health

Policy and Management, Erasmus

University, P.O. Box 1738, Rotterdam

3000 DR, Netherlands

e-mail:cramm@bmg.eur.nl
Purpose: To (i) investigate the influence of general self-efficacy on quality of life outcomes over time among adolescents with type I diabetes or juvenile rheumatoid arthritis (JRA), (ii) investigate parents' perceptions of general self-efficacy and quality of life of adolescents with diabetes or JRA over time, and (iii) identify possible differences in the evaluations of adolescents and parents.

Methods: This study included adolescents aged 12-25 years with type I diabetes or JRA and their parents. At T1, 171/573 (30\% response rate) adolescents with diabetes or JRA and 229/563 (41\% response rate) parents completed the questionnaire. At T2, 230/551 (42\% response rate) adolescents and 220/559 (39\% response rate) parents still participating in the study completed the questionnaire. A total of 112 adolescents and 143 parents filled in the questionnaires at both $\mathrm{T} 1$ and $\mathrm{T} 2$.

Results: Adolescents perceived significant improvement in their general self-efficacy and reduced quality of life over time, whereas parents' perceptions did not change. According to adolescents and parents, physical functioning was better among adolescents with diabetes than among those with JRA. Regression analyses of adolescents' data showed that general self-efficacy at T1 $(\beta=0.13 ; p \leq 0.10)$ and changes in general self-efficacy $(\beta=0.22$; $p \leq 0.01$ ) predicted quality of life at T2. Parents' responses revealed that adolescents' general self-efficacy atT1 $(\beta=0.16 ; p \leq 0.05)$ and changes in adolescents' general self-efficacy $(\beta=0.18 ; p \leq 0.05)$ predicted adolescents' quality of life at $\mathrm{T} 2$.

Conclusion: General self-efficacy and changes therein positively affected quality of life in adolescents with diabetes or JRA over time, as perceived by adolescents and parents. These findings emphasize the need for the implementation of interventions aiming to improve general self-efficacy in these populations.

Keywords: self-efficacy, quality of life, chronic illness, adolescent, parent, diabetes, juvenile rheumatoid arthritis

\section{INTRODUCTION}

Chronically ill adolescents such as those with type I diabetes or juvenile rheumatoid arthritis (JRA) must deal with taking medication, engaging in daily physical activity, maintaining a healthy diet, and proper disease management to reduce the negative effects of the disease on their quality of life (1-3).

The most common symptoms of type I diabetes are blurred vision, decreased mental sharpness, extreme thirst and hunger, fatigue, the frequent need to urinate, frequent skin infections, weight loss (despite increased appetite), and slow-healing wounds.

The most common symptoms of all forms of JRA include joint pain and swelling, which may come and go but are most often persistent; joint stiffness in the morning; limping; and unpredictable changes in symptoms from asymptomatic periods (remission) to flare-ups and pain. The long-term effects of JRA include joint contracture and joint damage.
Although JRA and diabetes differ in their origin and symptoms, both conditions require constant monitoring to avoid complications and effective disease management (e.g., treatment compliance, healthy diet, taking medication, pain management, physical activities) is similar for adolescents with these conditions (4). Investigating and comparing their quality of life could increase our understanding of how different diseases may or may not differentially affect quality of life (5).

Self-efficacy is important for effective disease management. Research has shown that self-efficacy predicts adherence (taking medication), health behavior (physical activities), effective pain management, and disease management (6-14), which are expected to be important for quality of life. While diabetes and JRA are conditions with unique aspects, they also have comparable self-efficacy tasks, such as managing symptoms and treatment, forming relationships with care providers, maintaining a positive self-image, 
and preparing for an uncertain future (4). Use of a generic selfefficacy measure instead of a disease specific self-efficacy measure enables the comparison of adolescents with diabetes and those with JRA, which may be useful in predicting health behaviors and quality of life across conditions. General self-efficacy refers to the belief in one's competence to attempt difficult or novel tasks, and to cope with adversity arising from specific demanding situations (15-18). When setbacks occur, adolescents with higher levels of general self-efficacy may recover more quickly and remain committed to their goals. As such, general self-efficacy is considered to be an important factor in coping with the challenges and demands presented by these chronic conditions during adolescence (1).

Longitudinal studies showed that self-efficacy predicts quality of life among patients with multiple sclerosis (19), myocardial infarction (20), cancer (21,22), arthritis (23), and Chronic Obstructive Pulmonary Disease (24). Cramm and colleagues (1) also found a cross-sectional relationship between general selfefficacy of adolescents with a variety of chronic conditions and their quality of life, but a lack of longitudinal studies investigating if this relationship among adolescents with JRA or diabetes over time persists. Since earlier longitudinal studies showed that self-efficacy predicted quality of life among patients with other chronic conditions the hypothesis of this study is that self-efficacy also predicts quality of life among adolescents with diabetes and JRA. Furthermore, it remains unknown whether this relationship differs across conditions. The first aim of this study is to investigate the influence of general self-efficacy on quality of life outcomes over time among adolescents with diabetes or JRA. Since self-efficacy is thought of to be modifiable through intervention, it may be used to improve quality of life of chronically ill adolescents.

Adolescent and proxy reports from parents are often used in pediatric and adolescent care and discrepancies between adolescents' and parents' perceptions of adolescents' quality of life have been identified, but research comparing the longitudinal relationship between adolescents and proxy reports from parents of changes in adolescents' general self-efficacy skills and quality of life over time is lacking. Therefore, the second aim of this study is to investigate parents' perceptions of general self-efficacy and quality of life of adolescents with diabetes or JRA over time. Studying the effects of general self-efficacy and changes therein on quality of life among adolescents with diabetes or JRA, as assessed by adolescents and parents over time allows us to compare their findings and identify possible differences in their evaluations (aim three).

\section{MATERIALS AND METHODS}

This longitudinal study surveyed adolescents with type I diabetes or JRA and their parents at two measurement points (T1 in 2010 and $\mathrm{T} 2$ in 2011). Mean time between T1 and T2 was $16.7 \pm 1.5$ (range 15-21) months. Eligible participants were 12-25-year-olds with diabetes or JRA in active pediatric follow-up (at least one contact moment in the past year) at participating hospital departments. These departments joined a quality improvement program called On Your Own Feet Ahead $(1,25)$. The aim of this program is to improve care for adolescents with diabetes or JRA in seven hospital departments in The Netherlands.
Approval for the study was obtained from the Erasmus Medical Center Institutional Review Board. Eligible adolescents and parents received written information and a unique access code, and were invited to complete an online questionnaire. Nonrespondents received a postal reminder after 2 weeks, including a printed copy of the questionnaire. At T1, 171 out of a total of 573 adolescents with diabetes or JRA (30\% response rate) filled in the questionnaire and 229 out of a total of 563 parents $(41 \%$ response rate) completed the questionnaire. At $\mathrm{T} 2$ all patients (and their parents) still included in the study were asked again to fill in the questionnaire. At T2, 230 out of 551 adolescents ( $42 \%$ response rate) and 220 out of 559 parents (39\% response rate) completed the questionnaire. A total of 112 adolescents and 143 parents filled in the questionnaires at both $\mathrm{T} 1$ and $\mathrm{T} 2$.

\section{MEASURES}

The 10-item general self-efficacy scale was used to assess adolescents' and parents' perceptions of self-efficacy in adolescents with diabetes or JRA (5). The ten items are: "I can always manage to solve difficult problems if I try hard enough," "if someone opposes me, I can find the means and ways to get what I want," "it is easy for me to stick to my aims and accomplish my goals," "I am confident that I could deal efficiently with unexpected events," "thanks to my resourcefulness, I know how to handle unforeseen situations," "I can solve most problems if I invest the necessary effort," "I can remain calm when facing difficulties because I can rely on my coping abilities," "when I am confronted with a problem, I can usually find several solutions," "if I am in trouble, I can usually think of a solution," and "I can usually handle whatever comes my way." Respondents were asked to rate their agreement with items on a four-point scale ranging from 1 ("not at all true") to 4 ("exactly true"). No time frame was provided in asking about perceptions of self-efficacy. Parents were asked to rate their agreement on how these items apply to their child using the same four-point scale. A total score (10-40) was obtained by summing the responses to each of the 10-items. Cronbach's alpha values of the general selfefficacy scale among adolescents at T1 (0.83) and T2 (0.88) and parents at T1 (0.93) and T2 (0.92) indicated excellent reliability.

The instrument has been widely used among adolescents, patients, and parents [e.g., Ref. (1, 26-29)] Evidence of the validity and predictive nature of the general self-efficacy scale has been previously published [e g., Ref. (30-35)]. These studies reported strong negative associations of general self-efficacy with, for example, depression, anxiety, stress, and burn-out and strong positive relationships were found with optimism.

Adolescents' and parents' perceptions of quality of life of adolescents with diabetes or JRA were assessed with the 37-item DISABKIDS condition-generic module questionnaire $(2,3)$. The DISABKIDS was specifically developed to assess quality of life among chronically ill children and adolescents (36). The DISABKIDS consists of four versions: a self-report version for children, a proxy version for parents and a child, and proxy version for those younger than 8 years (The DISABKIDS - Smileys measure). The 37-item DISABKIDS condition-generic module questionnaire which we used in our study contains six dimensions (independence, physical limitation, emotion, social exclusion, social inclusion, and treatment). Psychometric tests revealed that this instrument proved 
satisfactory internal consistency for all dimensions $(36,37)$ and showed satisfying results regarding the instrument's construct validity, convergent and discriminant validity $(37,38)$. Responses to each item are structured using a five-point Likert scale ranging from 1 ("never") to 5 ("always"). Following the method of the developers of the instrument overall quality of life scores were transformed linearly to a $0-100$ scale, with 100 indicating the highest quality of life. Cronbach's alpha values of the DISABKIDS condition-generic module among adolescents at T1 (0.82) and T2 (0.84) and parents at T1 (0.83) and T2 (0.85) indicated good internal reliability among our study sample.

The questionnaire further asked respondents to provide information about background variables, such as age and gender. In addition, to account for the severity of chronic conditions, we used the SF-20 physical functioning scale to assess adolescents' and parents' perceptions of physical functioning among adolescents with diabetes or JRA $(39,40)$. Physical functioning is assessed by limitations due to health in a variety of physical activities, ranging from strenuous to basic. Responses to each item are structured using a three-point Likert scale. The construction of this measure is described by Stewart and colleagues (41). Briefly, the SF-20 physical functioning scale obtains a score by summing the responses. The scores are reversed so that a high value indicates better physical functioning and is transformed linearly to range from 0 to 100 , with higher scores indicating higher levels of physical functioning. These transformations are based on developer instruction. Support for the reliability and construct validity of the SF-20 is provided in previously published documents [e.g., Ref. $(41,42)$ ].

\section{STATISTICAL ANALYSES}

Descriptive analyses included the calculation of means and standard deviations. Two-tailed, paired $t$-tests were used to investigate improvements in quality of life and general self-efficacy over time (T2-T1), as perceived by adolescents and parents. Differences in quality of life, general self-efficacy, age, gender, and physical functioning between adolescents with diabetes and those with JRA were established using chi-squared and two-tailed, independent sample $t$-tests. Next, we performed correlation analyses to identify significant relationships between background characteristics, self-efficacy at T1, and changes in self-efficacy and quality of life, as perceived by adolescents and parents. Point biserial correlation analyses were used to investigate the relationship between the dichotomous independent variables and quality of life. Significant variables in the univariate analyses were included in the multivariate analyses. Multiple regression analyses (using listwise deletion of missing cases) were then performed using data from adolescents and parents separately to determine whether general self-efficacy at $\mathrm{T} 1 \mathrm{and} /$ or changes in general self-efficacy predicted quality of life at T2, after controlling for significant background variables and quality of life at T1. We analyzed parents and adolescents separately (not as dyads). All statistical analyses were conducted with SPSS software (version 20.0; SPSS IBM).

\section{RESULTS}

About half (54.5\%) of the adolescents were female and their mean age was $16.0 \pm 2.3$ (range $12-22$ ) years. The majority $(66.4 \%)$ of the respondents reported having diabetes and $33.6 \%$ had JRA. The majority $(86 \%)$ of participating parents were mothers, and $14 \%$ were fathers. Parents' mean age was $47 \pm 4.9$ (range 36-66) years. Paired $t$-test results showed that adolescents perceived significant improvement in their general self-efficacy and reduced quality of life over time, whereas parents' perceptions did not change (Table 1).

Table 2 displays differences in quality of life, age, gender, physical functioning, and general self-efficacy between adolescents with diabetes and those with JRA, as perceived by adolescents. These results show that the level of physical functioning was significantly higher among adolescents with diabetes than among those with JRA ( 87.0 vs. $69.0, p \leq 0.001)$. No difference was found between groups in quality of life ( $\mathrm{T} 1$ or T2), age, gender, general self-efficacy at T1, or changes in general self-efficacy (T2-T1).

Table 3 presents differences in quality of life, age, gender, physical functioning, and general self-efficacy between adolescents with diabetes and those with JRA, as perceived by parents. According to the parents, physical functioning levels were also significantly higher among adolescents with diabetes than among those with JRA (93.0 vs. $66.2, p \leq 0.001$ ). Furthermore, parents perceived a greater degree of improvement in general self-efficacy among

Table 1 | Adolescents and parents' perceptions of changes in quality of life and general self-efficacy over time.

\begin{tabular}{|c|c|c|c|c|c|c|c|c|}
\hline & $N$ & \multicolumn{2}{|c|}{$\begin{array}{l}\text { Baseline } \\
\text { assessment } \\
(\mathrm{T} 1,2010)\end{array}$} & \multicolumn{2}{|c|}{$\begin{array}{l}\text { Follow-up } \\
\text { assessment } \\
(\mathrm{T} 2,2011)\end{array}$} & \multicolumn{3}{|c|}{ T2-T1 } \\
\hline \multicolumn{9}{|c|}{ ADOLESCENTS' PERCEPTIONS } \\
\hline Quality of life & 110 & 64.58 & $(11.32)$ & 62.75 & (12.04) & -1.84 & (9.29) & $<0.05$ \\
\hline \multicolumn{9}{|c|}{ PARENTS' PERCEPTIONS } \\
\hline Quality of life & 142 & 62.67 & (10.58) & 62.86 & (12.19) & 0.19 & (7.99) & 0.778 \\
\hline General self-efficacy & 142 & 30.39 & $(5.74)$ & 30.95 & $(5.38)$ & 0.56 & (4.95) & 0.186 \\
\hline
\end{tabular}

$M$, mean; SD, standard deviation.

a Paired t-test, T1 vs. T2. 
Table 2 | Background characteristics and perceived quality of life and general self-efficacy among adolescents with diabetes or juvenile rheumatoid arthritis.

\begin{tabular}{|c|c|c|c|c|c|c|c|}
\hline & & Total & JRA & Diabetes & $x^{2}$ & $t$ & $\boldsymbol{p}$ \\
\hline \multirow[t]{3}{*}{ Quality of life at T1 (2010) } & $n$ & 127 & 54 & 73 & & 1.368 & 0.174 \\
\hline & Mean & 65.3 & 67.0 & 64.1 & & & \\
\hline & $\mathrm{SD}$ & 11.8 & 12.8 & 11.0 & & & \\
\hline \multirow[t]{3}{*}{ Quality of life at T2 (2011) } & $n$ & 156 & 83 & 73 & & -0.009 & 0.993 \\
\hline & Mean & 62.4 & 62.4 & 62.4 & & & \\
\hline & $\mathrm{SD}$ & 11.4 & 9.9 & 12.9 & & & \\
\hline \multirow[t]{3}{*}{ Age (years) at T1 } & $n$ & 127 & 54 & 73 & & 0.087 & 0.931 \\
\hline & Mean & 16.0 & 16.0 & 15.9 & & & \\
\hline & $\mathrm{SD}$ & 2.2 & 2.6 & 1.9 & & & \\
\hline \multirow[t]{2}{*}{ Gender (female) at T1 } & $n$ & 127 & 54 & 73 & 0.312 & & 0.591 \\
\hline & $\%$ & 58.3 & 61.1 & 56.2 & & & \\
\hline \multirow[t]{3}{*}{ Physical functioning (SF-20) at T1 } & $n$ & 123 & 51 & 72 & & -3.718 & $\leq 0.001$ \\
\hline & Mean & 79.5 & 69.0 & 87.0 & & & \\
\hline & SD & 26.5 & 30.0 & 20.8 & & & \\
\hline \multirow[t]{3}{*}{ General self-efficacy at T1 } & $n$ & 127 & 54 & 73 & & 1.089 & 0.278 \\
\hline & Mean & 29.4 & 29.9 & 29.1 & & & \\
\hline & $\mathrm{SD}$ & 4.2 & 4.7 & 3.8 & & & \\
\hline \multirow[t]{3}{*}{ Changes in general self-efficacy (T2-T1) } & $n$ & 112 & 39 & 73 & & -1.642 & 0.103 \\
\hline & Mean & 1.4 & 0.5 & 1.9 & & & \\
\hline & SD & 4.3 & 5.0 & 3.8 & & & \\
\hline
\end{tabular}

JRA, juvenile rheumatoid arthritis; SD, standard deviation.

Results are based on respondents who filled in questionnaires at both T1 and T2 only.

adolescents with JRA than among those with diabetes (1.7 vs. -0.1 , $p \leq 0.05)$. No difference was found between groups in parents' perceptions of adolescents' quality of life (T1 or T2), parents' age or gender, or parents' perceptions of adolescents' general self-efficacy at $\mathrm{T} 1$.

Univariate analyses of adolescents' perceptions showed that quality of life at T1 $(p \leq 0.001)$, physical functioning $(p \leq 0.05)$, general self-efficacy at T1 $(p \leq 0.01)$, and changes in general selfefficacy $(p \leq 0.05)$ were all positively associated with quality of life at T2 (Table 4). A negative relationship was found between female gender and quality of life at T2 $(p \leq 0.01)$. No significant relationship was found between quality of life at T2 and adolescents' age or type of chronic condition.

Correlation analyses of parents' perceptions showed that adolescents' quality of life at T1 $(p \leq 0.001)$, adolescents' general self-efficacy at T1 $(p \leq 0.05)$, and changes in adolescents' general self-efficacy (T2-T1, $p \leq 0.01$ ) were positively related to parents' perceptions of adolescents' quality of life at T2 (Table 5). A negative relationship was found between female gender of adolescents, female gender of parents and quality of life at T2 (both $p \leq 0.01$ ). No significant relationship was found between quality of life at T2 and parents' or adolescents' age, type of chronic condition, or physical functioning.

Table 6 displays adolescents' perceptions of quality of life predictors among adolescents with diabetes or JRA at T2, as assessed by multiple regression analyses. After controlling for quality of life at T1, gender, and physical functioning, general self-efficacy at T1 $(\beta=0.13, p \leq 0.05)$ and changes in general self-efficacy $(\beta=0.22$, $p \leq 0.001)$ predicted quality of life at T2. The multiple regression model explained $52.3 \%$ of variance.

Parents' perceptions of quality of life predictors for adolescents with JRA or diabetes are displayed in Table 7. After controlling for quality of life at T1 and parents' and adolescents' genders, general self-efficacy at T1 $(\beta=0.16, p \leq 0.05)$ and changes in general self-efficacy $(\beta=0.18, p \leq 0.05)$ predicted adolescents' quality of life at T2. The multiple regression model explained $59.5 \%$ of variance.

\section{DISCUSSION}

Purpose of this study was to (i) investigate the influence of general self-efficacy on quality of life outcomes over time among adolescents with type I diabetes or JRA, (ii) to investigate parents' perceptions of general self-efficacy and quality of life of adolescents with diabetes or JRA over time, and (iii) identify possible differences in the evaluations of adolescents and parents.

The mean general self-efficacy scale scores for adolescents with diabetes or JRA (29.4) and their parents (30.4) in this study sample were comparable to those among average students without (known) health conditions in various countries (range 29.4-33.4) (18). The adolescents in this study were equally confident in their abilities to deal with demanding and difficult situations as are their peers, despite having diabetes or JRA. Our findings confirmed our 
Table 3 | Parents' background characteristics and perceived quality of life and general self-efficacy of adolescents with diabetes or juvenile rheumatoid arthritis

\begin{tabular}{|c|c|c|c|c|c|c|c|}
\hline & & Total & JRA & Diabetes & $x^{2}$ & $\boldsymbol{t}$ & $p$ \\
\hline \multirow[t]{3}{*}{ Parents' perceptions of adolescents' quality of life at T1 (2010) } & $n$ & 169 & 77 & 92 & & 0.589 & 0.556 \\
\hline & Mean & 63.2 & 63.7 & 62.7 & & & \\
\hline & SD & 11.0 & 10.2 & 11.6 & & & \\
\hline \multirow[t]{3}{*}{ Parents' perception of adolescents' quality of life at T2 (2011) } & $n$ & 169 & 76 & 93 & & -0.821 & 0.413 \\
\hline & Mean & 62.4 & 61.6 & 63.1 & & & \\
\hline & $\mathrm{SD}$ & 11.8 & 10.0 & 13.1 & & & \\
\hline \multirow[t]{3}{*}{ Age of parents (years) at T1 } & $n$ & 161 & 72 & 89 & & -1.017 & 0.311 \\
\hline & Mean & 46.9 & 46.5 & 47.2 & & & \\
\hline & $\mathrm{SD}$ & 4.8 & 5.3 & 4.4 & & & \\
\hline \multirow[t]{2}{*}{ Gender of parents (female) at T1 } & $n$ & 165 & 75 & 147 & 0.045 & & 1.000 \\
\hline & $\%$ & 87.3 & 86.7 & 87.8 & & & \\
\hline \multirow[t]{3}{*}{ Parents' perceptions of adolescents' physical functioning (SF-20) at T1 } & $n$ & 169 & 76 & 93 & & -6.457 & $\leq 0.001$ \\
\hline & Mean & 81.0 & 66.2 & 93.0 & & & \\
\hline & $\mathrm{SD}$ & 28.3 & 33.7 & 14.6 & & & \\
\hline \multirow[t]{3}{*}{ Parents' perceptions of adolescents' general self-efficacy at T1 } & $n$ & 169 & 77 & 92 & & -0.335 & 0.738 \\
\hline & Mean & 30.4 & 30.2 & 30.5 & & & \\
\hline & SD & 5.9 & 6.4 & 5.4 & & & \\
\hline \multirow[t]{3}{*}{ Parents' perceptions of changes in adolescents' general self-efficacy (T2-T1) } & $n$ & 142 & 50 & 92 & & 2.022 & $\leq 0.05$ \\
\hline & Mean & 0.6 & 1.7 & -0.1 & & & \\
\hline & SD & 5.0 & 4.3 & 5.2 & & & \\
\hline
\end{tabular}

JRA, juvenile rheumatoid arthritis; sd, standard deviation.

Results are based on respondents who filled in questionnaires at both T1 and T2 only.

Table 4 | Correlations with quality of life in adolescents with diabetes or juvenile rheumatoid arthritis at T2 (2011): adolescents' perceptions.

\begin{tabular}{ll}
\hline & \multicolumn{1}{c}{$\begin{array}{c}\text { Quality of life at T2 } \\
(\mathbf{2 0 1 1})(\boldsymbol{n}=\mathbf{1 1 0})\end{array}$} \\
\cline { 2 - 2 } & \multicolumn{1}{c}{$\mathbf{t}^{\mathbf{a}}$} \\
\hline Quality of life at T1 (2010) & $0.69^{* * *}$ \\
Age (years) at T1 & 0.08 \\
Gender (female) at T1 & \\
Type of chronic condition (JRA) at T1 & 0.644 \\
Physical functioning (SF-20) at T1 & $0.18^{*}$ \\
General self-efficacy at T1 & $0.22^{* *}$ \\
Changes in general self-efficacy (T2-T1) & $0.20^{*}$ \\
\hline
\end{tabular}

${ }^{*}{ }^{*} p \leq 0.001 ;{ }^{*} p \leq 0.01 ;{ }^{*} p \leq 0.05$ (one-sided).

$J R A$, juvenile rheumatoid arthritis.

${ }^{a}$ Point biserial correlations.

expectations that general self-efficacy and changes therein would affect quality of life in these adolescents.

We found significant univariate and multivariate relationships between general self-efficacy and changes therein on quality of life at T2, even after controlling for quality of life at T1, age, gender, and type of chronic condition. We also found evidence for a longitudinal relationship between changes in general self-efficacy and quality of life of chronically ill adolescents, according to adolescents' and parents' perspectives. These findings emphasize the importance of attention to general self-efficacy skills among adolescents with diabetes or JRA.

An interesting difference found in the longitudinal perspectives of adolescents and parents is that while adolescents perceived general self-efficacy to improve and quality of life to decline over time, parents' perceptions of their children's general efficacy and quality of life did not change over time. A reduction in quality of life over time has also been identified in adolescents with physical disabilities (43) and "healthy" adolescents (44). This decrease may be explained by the important life transitions through which these individuals pass as they enter adulthood. Furthermore, in a longitudinal study of healthy adolescents' and parents' perceptions of adolescents' quality of life, Jozefiak and colleagues (44) also found that adolescents reported a reduction in quality of life while parents perceived no significant change. These results indicate that self-reports and proxy reports from parents are not interchangeable. Parents may not be aware of changes experienced by chronically ill adolescents, or their effects on general self-efficacy and quality of life. A focus on adolescents' as well as parents' perceptions is therefore recommended.

In addition to investigating the longitudinal relationship between general self-efficacy and quality of life, we also 
Table 5 | Correlations with quality of life in adolescents with diabetes or juvenile rheumatoid arthritis at T2 (2011): parents' perceptions.

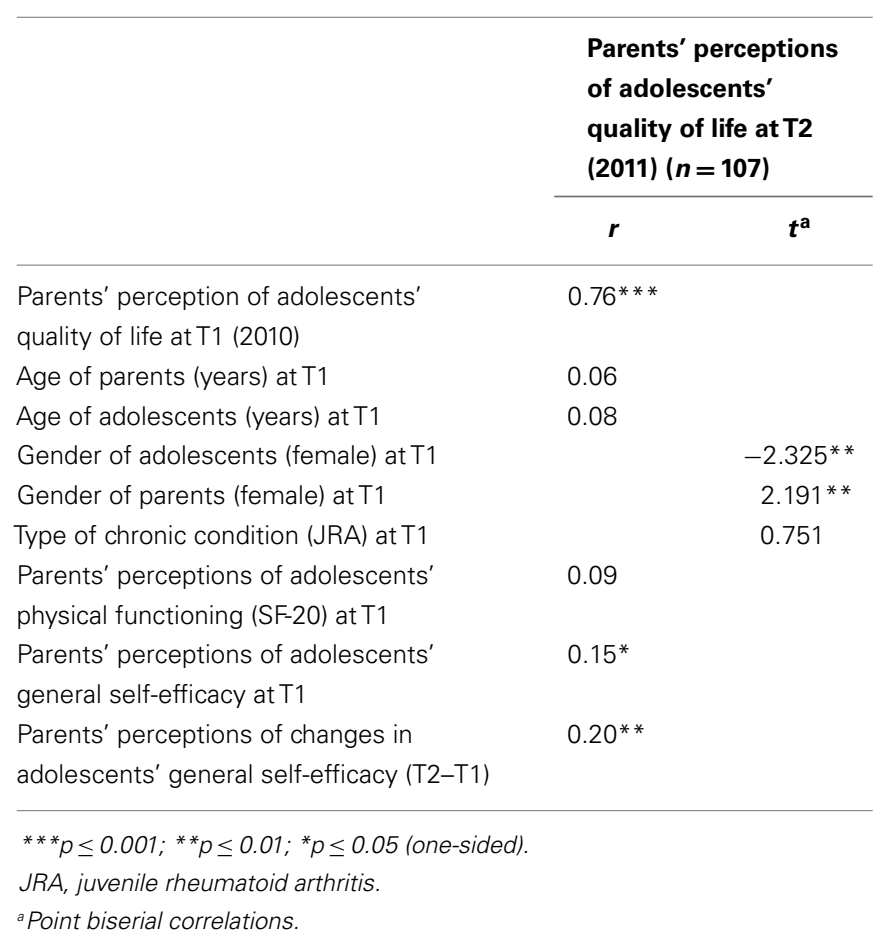

Table 6 | Quality of life predictors in adolescents with diabetes or juvenile rheumatoid arthritis at T2 (2011; multiple regression): adolescents' perceptions

\begin{tabular}{lc}
\hline & $\begin{array}{c}\text { Quality of life at T2 } \\
\text { (2011) }(\boldsymbol{n}=\mathbf{1 0 7})\end{array}$ \\
\hline Quality of life at T1 (2010) & $0.66^{* *}$ \\
Gender (female) at T1 & $-0.13^{*}$ \\
Physical functioning (SF-20) at T1 & -0.10 \\
General self-efficacy at T1 & $0.13^{*}$ \\
Changes in general self-efficacy (T2-T1) & $0.22^{* * *}$ \\
Adjusted $R^{2}$ & $52.3 \%$ \\
$F$ & 24.458
\end{tabular}

${ }^{* *} p \leq 0.001 ;{ }^{*} p \leq 0.05$ (one-sided).

investigated differences in quality of life, age, gender, physical functioning, and general self-efficacy between adolescents with diabetes and those with JRA, as perceived by adolescents and parents. The results revealed a significant difference in the level of physical functioning; adolescents with diabetes and their parents reported much higher levels of physical functioning than did those with JRA. Adolescents' perceived quality of life, self-efficacy, and changes in general self-efficacy did not differ between chronic conditions.

The most important limitation of our study was the low response rate at $\mathrm{T} 1$ and $\mathrm{T} 2$; non-response bias may have influenced our study findings. However, these rates are similar to those reported in other studies in which respondents received questionnaires by mail $(45,46)$. The major strength of our study is
Table 7 | Quality of life predictors in adolescents with diabetes or juvenile rheumatoid arthritis at T2 (2011; multiple regression): parents' perceptions

\begin{tabular}{lc}
\hline & $\begin{array}{l}\text { Parents' perceptions } \\
\text { of adolescents' } \\
\text { quality of life at T2 } \\
\text { (2011) ( } \mathbf{n = 1 0 5 )}\end{array}$ \\
\hline $\begin{array}{lc}\text { Parents' perception of adolescents' quality of } \\
\text { life at T1 (2010) }\end{array}$ & $0.67^{* * *}$ \\
Gender of adolescents (female) at T1 & -0.06 \\
Gender of parents (female) at T1 & -0.09 \\
Parents' perceptions of adolescents' general & $0.16^{*}$ \\
self-efficacy at T1 & $0.18^{*}$ \\
Parents' perceptions of changes in adolescents' & $59.5 \%$ \\
general self-efficacy (T2-T1) & 26.571 \\
Adjusted $R^{2}$ & \\
$F$ & \\
\hline$* * * p \leq 0.001 ;{ }^{*} p \leq 0.05$ (one-sided). &
\end{tabular}

that we identified a longitudinal relationship between changes in self-efficacy and quality of life over time, according to adolescents and parents.

\section{CONCLUSION}

General self-efficacy and changes therein positively affected the quality of life of adolescents with diabetes or JRA over time, as perceived by adolescents and parents. Self-efficacy might be an important target of interventions for improving quality of life of chronically ill adolescents. These findings are important for professionals and health care organizations aiming to improve quality of life in adolescents with diabetes or JRA, and emphasize the need for the implementation of interventions aiming to improve general self-efficacy in these populations.

\section{ACKNOWLEDGMENTS}

This study was funded with a grant from the Netherlands organization for health research and development (ZonMw; grant number: 157002014). The views are those of the authors. The authors acknowledge the participating adolescents and parents, and the hospital departments for their support in recruiting the participants in this study: Maasstad Hospital (Diabetes), Amphia Hospital (Pediatric Diabetes), Meander Medical Center (Pediatric Diabetes), Catharina Hospital (Pediatric Diabetes), Sint Maartenskliniek (Rheumatology), Erasmus Medical Center (Rheumatology), and the VU Medical Center (Diabetes).

\section{REFERENCES}

1. Cramm JM, Strating MMH, Sonneveld HM, Nieboer AP. The longitudinal relationship between satisfaction with transitional care and social and emotional quality of life among chronically ill adolescents. Appl Res Qual Life (2013) 8:481-91. doi:10.1007/s11482-012-9209-3

2. Leganger A, Kraft P, Røysamb E. Perceived self-efficacy in health behaviour research: conceptualisation, measurement and correlates. Psychol Health (2000) 15:51-69. doi:10.1080/08870440008400288

3. Luszczynska A, Scholz U, Schwarzer R. The general self-efficacy scale: multicultural validation studies. J Psychol (2005) 139(5):439-57. doi:10.3200/JRLP.139. 5.439- 457 
4. Moos RH, Holahan CJ. Adaptive tasks and methods of coping with illness and disability. In: Martz E, Livnah H, editors. Coping with Chronic Disease and Disability: Theoretical, Empirical, and Clinical Aspects. New York: Springer (2007). p. 107-26.

5. Schwarzer R, Jerusalem M. Generalized self-efficacy scale. In: Weinmann J, Wright S, Johnston M, editors. Measures in Health Psychology: A User's Portfolio. Causal and Control Beliefs. Windsor: Nfer-Nelson (1995). p. 35-7.

6. Andre M, Hedengren E, Hagelberg S, Stenstrom CH. Perceived ability to manage juvenile chronic arthritis among adolescents and parents: development of a questionnaire to assess medical issues, exercise, pain, and social support. Arthritis Care Res (1999) 12:229-37. doi:10.1002/1529-0131(199908)12:4<229::AIDART1>3.3.CO;2-A

7. Bar-Mor G, Bar-Tal Y, Krulik T, Zeevi B. Self-efficacy and physical activity in adolescents with trivial, mild or moderate congenital cardiac malformations. Cardiol Young (2000) 10:561-6. doi:10.1017/S1047951100008829

8. van Es SM, Kaptein AA, Bezemer PD, Nagelkerke AF, Colland VT, Bouter LM. Predicting adherence to prophylactic medication in adolescents with asthma: an application of ASE-model. Patient Educ Couns (2002) 47:165-71. doi:10.1016/S0738-3991(01)00195-1

9. Griva K, Myers LB, Newman S. Illness perceptions and self-efficacy beliefs in adolescents and young adults with insulin dependent diabetes mellitus. Psychol Health (2000) 15:733-50. doi:10.1080/08870440008405578

10. Luszczynska A, Gibbons FX, Piko B, Tekozel M. Self-regulatory cognitions, social comparison, and perceived peers' behaviors as predictors of nutrition and physical activity: a comparison among adolescents in Hungary, Poland, Turkey, and USA. Psychol Health (2004) 19:577-93. doi:10.1080/0887044042000205844

11. Luszczynska A, Cao DS, Mallach N, Pietron K, Mazurkiewicz M, Schwarzer R. Intentions, planning, and self-efficacy predict physical activity in Chinese and Polish adolescents: two moderated mediation analyses. Int J Clin Health Psychol (2010) 10(2):265-78.

12. Morisky DE, Malotte CK, Ebin V, Davidson P, Cabrera D, Trout PT, et al. Behavioral interventions for the control of tuberculosis among adolescents. Public Health Rep (2001) 116:568-74. doi:10.1016/S0033-3549(04)50089-4

13. Ott J, Greening L, Palardy N, Holderby A, DeBell WK. Self-efficacy as a mediator variable for adolescents' adherence to treatment for insulindependent diabetes mellitus. Child Health Care (2000) 29:47-63. doi:10.1207/ S15326888CHC2901_4

14. Schwarzer R, Fuchs R. Self-efficacy and health behaviors. In: Conner M, Norman P, editors. Predicting Health Behavior: Research and Practice with Social Cognition Models. Buckingham: Open University Press (1996). p. 163-96.

15. Bandura A. Self-Efficacy: The Exercise of Control. New York: W. H. Freeman and Company (1997).

16. Bandura A. A social cognitive theory of personality. 2nd ed. In: Pervin L, John O, editors. Handbook of Personality. New York: Guilford Press (1999). p. $154-96$.

17. Cross MJ, March LM, Lapsley HM, Byrne E, Brooks PM. Patient self-efficacy and health locus of control: relationships with health status and arthritisrelated expenditure. Rheumatology (Oxford) (2006) 45:92-6. doi:10.1093/ rheumatology/keil14

18. Luszczynska A, Gutiérrez-Doña B, Schwarzer R. General self-efficacy in various domains of human functioning: evidence from five countries. Int J Psychol (2005) 40(2):80-9. doi:10.1080/00207590444000041

19. Motl RW, McAuley E, Wynn D, Sandroff B, Suh Y. Physical activity, self-efficacy, and health-related quality of life in persons with multiple sclerosis: analysis of associations between individual-level changes over one year. Qual Life Res (2013) 22(2):253-61. doi:10.1007/s11136-012-0149-z

20. Brink E, Alsén P, Herlitz J, Kjellgren K, Cliffordson C. General self-efficacy and health-related quality of life after myocardial infarction. Psychol Health Med (2012) 17(3):346-55. doi:10.1080/13548506.2011.608807

21. Heckman JE, Chamie K, Maliski SL, Fink A, Kwan L, Connor SE, et al. The role of self-efficacy in quality of life for disadvantaged men with prostate cancer. J Urol (2011) 186(5):1855-61. doi:10.1016/j.juro.2011.06.059

22. Haas BK. Fatigue, self-efficacy, physical activity, and quality of life in women with breast cancer. Cancer Nurs (2011) 34(4):322-34. doi:10.1097/NCC. 0b013e3181f9a300

23. Knittle KP, De Gucht V, Hurkmans EJ, Vlieland TP, Peeters AJ, Ronday HK, et al. Effect of self-efficacy and physical activity goal achievement on arthritis pain and quality of life in patients with rheumatoid arthritis. Arthritis Care Res (Hoboken) (2011) 63(11):1613-9. doi:10.1002/acr.20587
24. Bentsen SB, Wentzel-Larsen T, Henriksen AH, Rokne B, Wahl AK. Self-efficacy as a predictor of improvement in health status and overall quality of life in pulmonary rehabilitation - an exploratory study. Patient Educ Couns (2010) 81(1):5-13. doi:10.1016/j.pec.2009.11.019

25. Sonneveld HM, Strating MMH, van Staa AL, Nieboer AP. Gaps in transitional care: what are the perceptions of adolescents, parents and providers? Child Care Health Dev (2012) 39:69-80. doi:10.1111/j.1365-2214. 2011.01354.x

26. Haugland T, Veenstra M, Vatn MH, Wahl AK. Improvement in stress, general selfefficacy, and health related quality of life following patient education for patients with neuroendocrine tumors: a pilot study. Nurs Res Pract (2013) 2013:695820. doi:10.1155/2013/695820

27. Miniszewska J, Juczynski Z, Ograczyk A, Zalewska A. Health-related quality of life in psoriasis: important role of personal resources. Acta Derm Venereol (2013) 93(5):551-6. doi:10.2340/00015555-1530

28. Li Y, Cao F, Cao D, Wang Q, Cui N. Predictors of posttraumatic growth among parents of children undergoing inpatient corrective surgery for congenital disease. J Pediatr Surg (2012) 47(11):2011-21. doi:10.1016/j.jpedsurg.2012. 07.005

29. Vangberg HC, Lillevoll KR, Waterloo K, Eisemann M. Does personality predict depression and use of an internet-based intervention for depression among adolescents? Depress Res Treat (2012) 2012:593068. doi:10.1155/2012/ 593068

30. Schwarzer R, Born A. Optimistic self-beliefs: assessment of general perceived self-efficacy in thirteen cultures. World Psychol (1997) 3:177-90.

31. Schwarzer R, BaBler J, Kwiatek P, Schroder K. The assessment of optimistic self-beliefs: comparison of the German, Spanish, and Chinese versions of the general self-efficacy scale. Appl Psychol (1997) 46(1):69-88. doi:10.1111/j.14640597.1997.tb01096.x

32. Schwarzer R, Jerusalem M, editors. Skalen zur Erfassung von Lehrer-und Schülermerkmalen: Dokumentation der Psychometrischen Verfahren im Rahmen der Wissenschaftlichen Begleitung des Modellversuchs Selbstwirksame Schulen. Berlin: Freie Universität Berlin (1999).

33. Schwarzer R, Schmitz GS, Tang C. Teacher burnout in Hong Kong and Germany: a cross-cultural validation of the Maslach Burnout Inventory. Anxiety Stress Coping (2000) 13:309-26. doi:10.1080/10615800008549268

34. Scholz U, Gutiérrez-Doña B, Sud S, Schwarzer R. Is general self-efficacy a universal construct? Psychometric findings from 25 countries. Eur J Psychol Assess (2002) 18(3):242-51. doi:10.1027//1015-5759.18.3.242

35. Schwarzer R, Hallum S. Perceived teacher self-efficacy as a predictor of job stress and burnout: mediation analyses. Appl Psychol (2008) 57:152-71. doi:10.1111/ j.1464-0597.2008.00359.x

36. The European DISABKIDS Group. The DISABKIDS Questionnaires: Quality of Life Questionnaires for Children with Chronic Conditions. Lengerich: Pabst Science Publishers (2006).

37. Simeoni MC, Schmidt S, Muehlan H, Debensason D, Bullinger M; DISABKIDS Group. Field testing of a European quality of life instrument for children and adolescents with chronic conditions: the 37-item DISABKIDS Chronic Generic Module. Qual Life Res (2007) 16(5):881-93. doi:10.1007/s11136-0079188-2

38. af Sandeberg M, Johansson EM, Hagell P, Wettergren L. Psychometric properties of the DISABKIDS Chronic Generic Module (DCGM-37) when used in children undergoing treatment for cancer. Health Qual Life Outcomes (2010) 8:109. doi:10.1186/1477-7525-8-109

39. Carver DJ, Chapman CA, Thomas VS, Stadnyk KJ, Rockwood K. Validity and reliability of the Medical Outcomes Study Short Form-20 questionnaire as a measure of quality of life in elderly people living at home. Age Ageing (1999) 28(2):169-74. doi:10.1093/ageing/28.2.169

40. Kempen GI. Assessment of health status of the elderly. Application of a Dutch version of the MOS scale. Tijdschr Gerontol Geriatr (1992) 23(4):132-40.

41. Stewart A, Hays R, Ware J. The MOS Short-form General Health Survey. Reliability and validity in a patient population. Med Care (1988) 26(7):724-35. doi:10.1097/00005650-198807000-00007

42. Ware J, Sherbourne C, Davies A. Developing and testing the MOS 20-item shortform health survey: a general population application. In: Stewart A, Ware J, editors. Measuring Functioning and Well-Being: The Medical Outcomes Study Approach. Durham, NC: Duke University Press (1992). p. 277-90.

43. Lin JH, Ju YH, Lee SJ, Yang YH, Lo SK. Examining changes in self-perceived quality of life in children and adolescents with physical disability using a longitudinal 
design. Disabil Rehabil (2011) 33(19-20):1873-9. doi:10.3109/09638288.2011. 552664

44. Jozefiak T, Larsson B, Wichstrøm L. Changes in quality of life among Norwegian school children: a six-month follow-up study. Health Qual Life Outcomes (2009) 7:7. doi:10.1186/1477-7525-7-7

45. Buttle F, Thomas G. Questionnaire colour and mail survey response rate. J Mark Res Soc (1997) 39:625-6.

46. Picavet HSJ. National health surveys by mail or home interview. Effects on response. J Epidemiol Community Health (2001) 55:408-13. doi:10.1136/jech. 55.6 .408

Conflict of Interest Statement: The authors declare that the research was conducted in the absence of any commercial or financial relationships that could be construed as a potential conflict of interest.
Received: 18 June 2013; accepted: 07 November 2013; published online: 20 November 2013.

Citation: Cramm JM, Strating MMH and Nieboer AP (2013) The importance of general self-efficacy for the quality of life of adolescents with diabetes or juvenile rheumatoid arthritis over time: a longitudinal study among adolescents and parents. Front. Pediatr. 1:40. doi: 10.3389/fped.2013.00040

This article was submitted to Child Health and Human Development, a section of the journal Frontiers in Pediatrics.

Copyright $\odot 2013$ Cramm, Strating and Nieboer. This is an open-access article distributed under the terms of the Creative Commons Attribution License (CC BY). The use, distribution or reproduction in other forums is permitted, provided the original author(s) or licensor are credited and that the original publication in this journal is cited, in accordance with accepted academic practice. No use, distribution or reproduction is permitted which does not comply with these terms. 